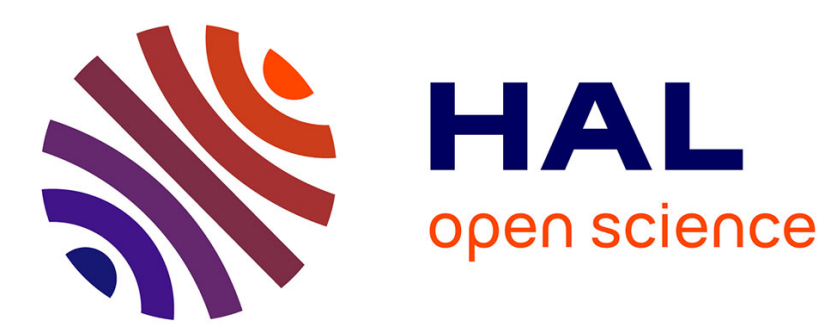

\title{
Artificial companion and acceptability a problem of design?
}

Sylvie Pesty, Dominique Duhaut

\section{To cite this version:}

Sylvie Pesty, Dominique Duhaut. Artificial companion and acceptability a problem of design? CogInfoCom 2012 * 3rd IEEE International Conference on Cognitive Infocommunications, Dec 2012, Slovenia. hal-00764351

\section{HAL Id: hal-00764351 \\ https://hal.science/hal-00764351}

Submitted on 12 Dec 2012

HAL is a multi-disciplinary open access archive for the deposit and dissemination of scientific research documents, whether they are published or not. The documents may come from teaching and research institutions in France or abroad, or from public or private research centers.
L'archive ouverte pluridisciplinaire HAL, est destinée au dépôt et à la diffusion de documents scientifiques de niveau recherche, publiés ou non, émanant des établissements d'enseignement et de recherche français ou étrangers, des laboratoires publics ou privés. 


\title{
Artificial companion and acceptability a problem of design?
}

\author{
Sylvie Pesty* and Dominique Duhaut ** \\ * UMR 5217 - Laboratory LIG, University of Grenoble, France \\ ** UMR 6285 - Lab-STICC, Université de Bretagne Sud, France \\ sylvie.pesty@imag.fr, dominique.duhaut@univ-ubs.fr
}

\begin{abstract}
We are in front of an evolution from traditional human-computer interactions to a kind of intense exchange between the human user and new generation of artificial systems. These systems can be virtual, Embodied Conversational Agents (ECAs), or real systems robots. We call these systems "artificial companions" that is to say systems with which the user wants to build a kind of life-long relationship.

In previous work [16] we study long term interaction and shown that emotions and personality are important features to establish this long relation. In this paper we want to go farther and discuss the set of dimensions to take into account to build an acceptable artificial companion.
\end{abstract}

\section{INTRODUCTION}

Designing a digital device that must interact with human is a difficult task because behind the quality of the service provided by the device, the human needs to accept to use the system. This problem of acceptability is studied from a long time. In this paper we want to propose a synthesis of acceptability criteria, to give guide line for the design of new product especially in the special case of artificial companion.

Human computer interaction is having a big evolution in these last years. The system is not any more an interface with a mouse and graphical objects moving on a screen but a set of multi-modal sensors that captures the position, acceleration, the voice ... coupled with virtual Embodied Conversational Agents (ECAs)- or real affective robots building a "embodied system". Then the some new capabilities are essential: gestures, facial expressions, gaze ... to build expressive systems able to express emotions, personality and presence. With this kind of new systems the human is not anymore "using" it but build a kind of relationship and the system is not anymore a tool but an "artificial companion".

In this paper, the section 2 will review criteria usually used to study the acceptability of digital interfaces. We present the practical and social acceptability and the consequences on the study of these interfaces with two dimensions of static criteria and dynamic criteria.

The section 3 will focus on digital machine that works with human to modify the environment, such ECA's or robots. This "co-activity" introduces new dimensions such cooperation between the human and the companion. This cooperation implies new dimensions for the acceptability, which are described.

The section 4 proposes to merge the criteria coming from interfaces and robots to give the significant dimensions of the acceptability problem for artificial companion.

Consequently, in section 5 we present the four minimal modules that must be integrated in the software architecture of the artificial companion to take into account all the criteria.

\section{FROM HUMAN-COMPUTER INTERACTION}

In this section we want to look to the evolution of the interaction with digital systems. The way of interaction is evolving with the use. For text edition or data management, windows with mouse or a pointing device are enough. But for new kind of applications, like psychological enrichment for instance or emotional interaction then other kind of interaction are expected.

In front of this evolution the problem of acceptability of these new systems is essential. The paper of Davis \& al [1] is a starting point of the study of this problem with the introduction of the TAM Technology Acceptance Model. Nielsen [2], in 1993, proposed a model of system acceptability (figure 1). We can see in this model that the acceptability is very oriented on the use of the system, not on human dimensions. Utility and Usability are the roots of the model. Just the satisfaction is mentioned but not really developed. 


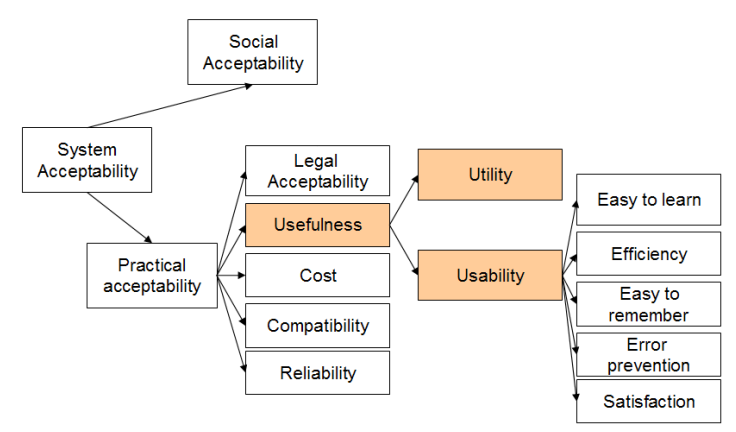

Figure 1: System acceptability from J. Nielsen [2]

In a second level of human-computer interactions, the usefulness of the interface is no longer the central notion, but the interaction becomes the fundamental point. This interaction is studied in four dimensions.

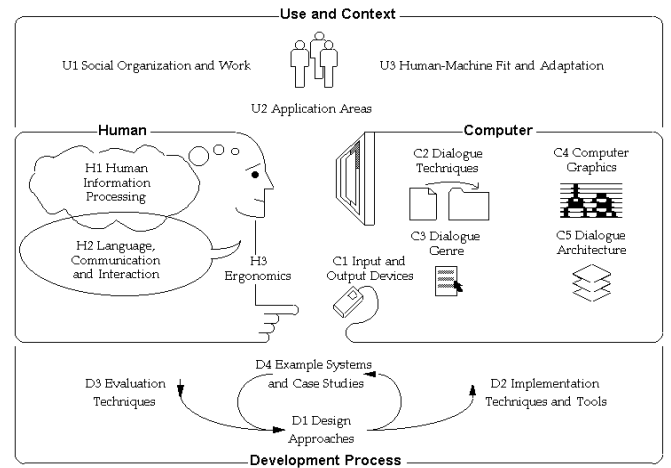

Figure 2: Human-Computer Interaction [3]

$\mathrm{HCI}$ is characterized by:

- Use and context of computers: human social organization and work, application areas, humanmachine fit and adaptation

- Human characteristics: human information processing, language, communication, interaction, ergonomics

- Computer system and interface architecture: input and output devices, dialogue techniques, dialogue genre, computer graphics, dialogue architecture

- Development process: design approaches, implementation techniques, evaluation techniques, example systems and case studies

From the point of view of acceptability of the interface of the robot by the human, these challenges are by a majority linked to social acceptability as developed by Ajzek [5] (figure 3).

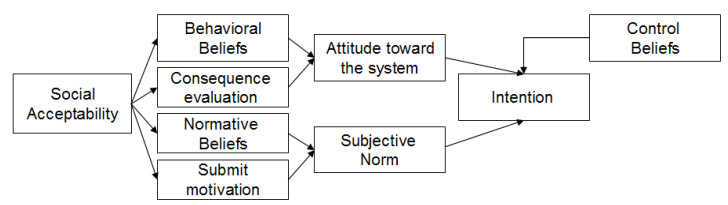

Figure 3: Planned behaviour from I. Ajzek [5]

As will be shown, they are no longer sufficient when considering significant human-system interaction. By significant interaction we mean interaction between a human and an intelligent real or virtual system which changes the quality of human life: for instance at home for disabled people. In this case, the problem is not to perform a task but to "feel good". This interaction introduces a new dimension which is no longer functional, but psychological. The issue then is creating an intelligent system that is "socially credible" (figure 4).

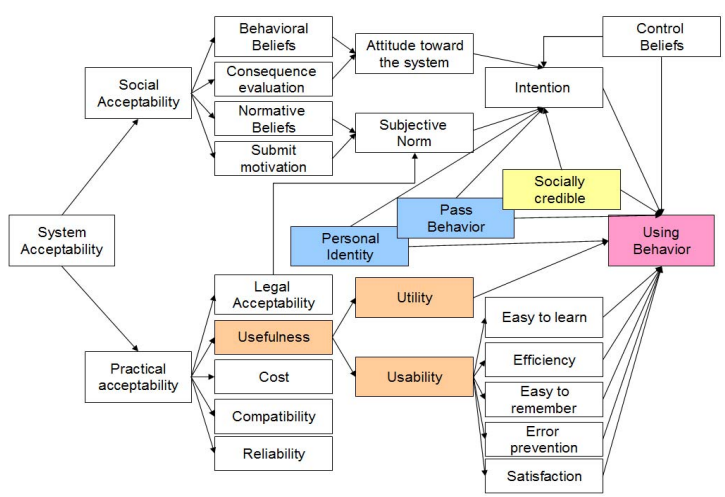

Figure 4: Our model including Socially credible [7].

In a previous work [7] we introduced two concepts. First is the "social credibility" (figure 4) between the human and his virtual system. It is based on social psychology works and it is well described in $[8,9]$. The notion of personal identity is the key of the credibility. A artificial system must express identity based on knowledge, values, personality and physical features like size, color ...

The interaction of identities to have a significant interaction from which the relationship can be built.

From psychology applied to interaction in computer science, Brangier \& all [14] define a list of criteria to measure persuasive dimensions. They are divided in two groups : static and dynamic criteria.

\section{Static criteria}

There are four dimensions

Credibility. It is the ability of the interface to inspire confidence and to make the user trust in the veracity of its 
information. It depends on reputation and notoriety. The credibility is stated in four components: Trustworthiness, Expertise, Trustfulness and Legitimacy.

Privacy. It is the security of personal data and the preservation of personal integrity. The privacy concerns: Safeness, Law respect feeling, Confidentiality.

Personalization. It is the concept of customization of the digital entity. The personalization includes: individualization and group membership.

Attractiveness. It is the use of aesthetics to create a positive emotion. Attractiveness has three components: Emotional appeal, Call to action and Tunneling design.

\section{Dynamic criteria}

There are four dimensions.

Solicitation It is refers to the first stage which initiates the relationship. It distinguish three elements: allusion, suggestion and teasing.

Initiation It refers to elements of the media that allow the first user-initiated. These elements may take the form of phishing and piloting the first steps.

Commitment It means that system continues to involve user through a process. It is described in three dimensions: Repeated request, Negative factors avoidance, Increased cost

Ascendency It is make the user use the media again. It is decomposed in three : Prescription of repetition, No-limit interactions, Pressure released

\begin{tabular}{|c|c|c|}
\hline \multirow{4}{*}{$\begin{array}{l}\text { Static } \\
\text { criteria }\end{array}$} & Credibility & $\begin{array}{l}\text { Trustworthiness } \\
\text { Expertise } \\
\text { Trustfulness } \\
\text { Legitimacy }\end{array}$ \\
\hline & Privacy & $\begin{array}{l}\text { Safeness } \\
\text { Law respect feeling } \\
\text { Confidentiality }\end{array}$ \\
\hline & Personalization & $\begin{array}{l}\text { Individualization } \\
\text { Group membership }\end{array}$ \\
\hline & Attractiveness & $\begin{array}{l}\text { Emotional attraction } \\
\text { Call to action } \\
\text { Tunneling design }\end{array}$ \\
\hline \multirow{4}{*}{$\begin{array}{l}\text { Dynam } \\
\text { ic } \\
\text { criteria }\end{array}$} & Solicitation & $\begin{array}{l}\text { Allusion } \\
\text { Teasing }\end{array}$ \\
\hline & Initiation & $\begin{array}{l}\text { Phishing } \\
\text { First action guidance }\end{array}$ \\
\hline & Commitment & $\begin{array}{l}\text { Repeated request } \\
\text { Negative factors avoidance } \\
\text { Increased cost }\end{array}$ \\
\hline & Ascendancy & $\begin{array}{l}\text { Prescription of repetition } \\
\text { No-limit interactions } \\
\text { Pressure released }\end{array}$ \\
\hline
\end{tabular}

Figure 4: Measuring persuasive dimensions in interfaces [14]
We see here that the problem is to evaluate computers interfaces but not artificial companion because the dimension of "doing together" or "act together" some task is not taken into account.

Let's now look to social robot research.

\section{FrOM SOCIAL ROBOT}

Following the ideas of C.Breazhal [6], we think that a robot could become a social object if we add some specific capabilities. We can then apply this companions [17]:

- The first capability would be social-cognitive skills. This means that the companion must appreciate : motivations, beliefs, norms, needs and all other mental states which are the proper of the behavior of a human

- The second capability is related to communication. The language used must be accessible and the enriched over long period of time because the communication is a co-construction. This is the base to build relationships

- The co-construction needs to have learning abilities. The mental state of the person is evolving based on his proper knowledge. The companion must follow this evolution to maintin the quality of the relationship

- Stress and pleasure are cirterias that the companion must also take into account in the context of heavy interaction [7]

Lastly the relationship between the companion and the human must bring to this last one fun. By this we mean being able to generate surprise and positive emotions when acting.

Over the social aspect the interaction with a robot is seen in [15] with its functionality has one of the dimension.

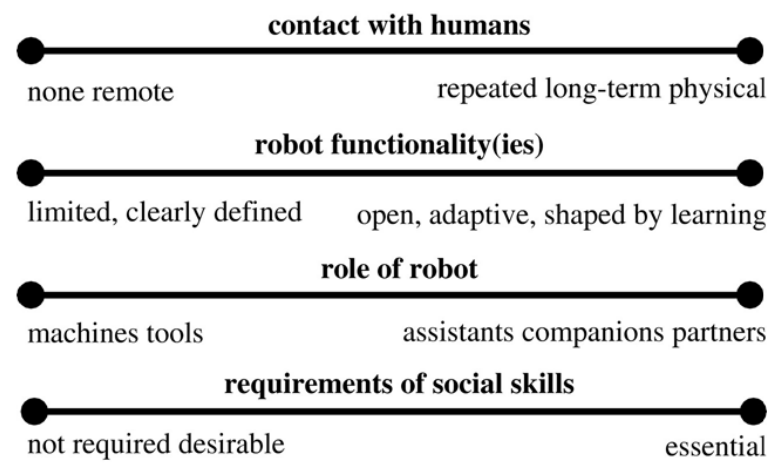

Based on this, we can now look to the team robots and humans and look to the dimensions proposed in this research area. 
If we have in mind to build a team of entities working together then we have to worry about the required properties. In their paper [4] four basic items are identifies and ten challenges are associated.

We can summarize their work in some requirements that the artificial companion must have.

Basic common background

The expectations of each member of the team must be the same or compatibles. The knowledge must have common roots. The social rules are shared. This means that the way of being, acting or speaking must respect the good manners

\section{Goal}

The general goal must be common between the members of the team. From the dynamical point of view this means that the goal must be expressed at the beginning and checked during the evolution of the work. Some intermediary goals can be based on team member expectation.

\section{Predictability}

During the common work it is essential to feel (and to be of course) secure. To reduce the stress of human the robot or the system must be predictable. This prediction is obtained by a preplanning of actions and by the explicit activity. The planning introduce the problems of leadership (who is, when) and negotiation

Here again, we can notice that the system is shown under performance and efficiency criteria, which are very deterministic. The mutual predictability protects from surprises coming either from the activity of the system or from the human.

Social acceptability is no doubt significant, but if we go ahead, and turn to "companions", that is to say robots or Embodied Conversational Agents (ECAs) with which the user wants to build a kind of life-long relationship, it is not sufficient and we must go beyond this concept of system acceptance.

Companion robots and companion agents both represent a new form of interaction with machines. Ideally, human users simply use natural language, and these companions, either virtual or physical, are endowed with refined communication capabilities and emotional expressivity. They are more natural, and closer to the human user. For ECA researchers, believability is a central concept. ECAs must be believable or credible; the most general of these terms is used to describe anything we accept as true, even in the absence of absolute proof. As stated by Bates [9], believability includes the appearance of reactivity, goals, situated social competence and emotions. In this regard, believable ECAs need both rational and emotional skills in order to exhibit a coherent and natural behaviour. Ortony, 2003, said that a major issue is to make an emotional agent a believable emotional agent. The same for companion robots that need to exhibit a coherent and natural behaviour and need to be "affective robots".

Therefore, the challenge for robot researchers and ECA researchers is the same: to build affective interacting companions which are not just practically and socially acceptable, but believable. But what about the interaction between the companion and the user? Even if the companion has refined communication capabilities and multimodal emotional expressivity, is it sufficient? We do not think it is, and we propose to overcome interaction and communication to go towards the concepts of impacting relation.

\section{ARTIFICIAL COMPANION DIMENSIONS}

Based on this analysis of interface evaluation and social functional aspects of robots we propose to summarize the design of acceptable robot with some new dimensions

We believe the artificial companion must respect all the static criteria defined in figure 4 . But to take into account social dimensions and functional dimensions in team work, we propose to add new criteria in the existing list of dynamic criteria.

\begin{tabular}{|c|c|c|}
\hline \multirow{4}{*}{$\begin{array}{l}\text { Dynamic } \\
\text { criteria }\end{array}$} & Solicitation & $\begin{array}{l}\text { Social norms on } \\
\text { communication }\end{array}$ \\
\hline & Initiation & Contract elaboration \\
\hline & Commitment & $\begin{array}{l}\text { Action } \\
\text { Engagement } \\
\text { Intention/predictability } \\
\text { Emotional state } \\
\text { Sincerity }\end{array}$ \\
\hline & Ascendancy & $\begin{array}{l}\text { Directability } \\
\text { Negotiation }\end{array}$ \\
\hline
\end{tabular}

Figure 5: Adding new criteria specific to companion

Social norms on communication: contrary to computer interface an artificial companion must respect some social norms to engage an activity. For instance must find an acceptable distance from the user (interpersonal distances), look to the user while speaking, open the communication with polite gesture, respect of speaking slot ...

Contract elaboration: if the user and the companion have to realize a task together then: goals must be defined and accepted together, role of each member must be define, the dangers and responsibilities in the task also..

Action: like precised in static criteria expertise imply that is a task is performed it is well done (secure, reliable). In a dynamic context the task must be done with a speed 
compatible with human to avoid making him afraid or without noise. A displacement in the space must take into account the presence of the human.

Engagement: during the co-activity human/companion the companion must check that the human is still engaged in the process, verify that the goal did not change for him, and what is the status to the goal.

Intention/predictability: to avoid accident or miss understanding the companion must be clear about his intention making him understandable and predictable by the human.

Emotional state: the companion must monitor the emotional state of the human for instance to wait if the human is getting tiered or to prevent a stress.

Sincerity: to maintain the commitment of the human in task he must perceive the companion as sincere. This dimension avoid also stress

Directability: the human can be the leader the task or the follower. This is a difficult part because it is linked to the trust you can have in the companion (can you accept to be directed by him) and also on the power authorized for him. Can he decide for you? Can he get anger against you?

Negotiation: is the counterpart of the directability. It we accept that the companion takes decisions we must be able to negotiate if we don't feel the decision as a right decision.

\section{FOUR DIMENSIONS FOR SOFTWARE}

Based on the previous sections we can describe the four necessary modules that must be present in software architecture for an acceptable artificial companion. We do not discuss here the dependencies of these modules.

\section{Goal management}

It is the place where the general schedule between all the potential tasks to be realised is decided. It answers the questions: What is the actual goal ? Do we agree on this goal ? How to reach this goal ? Who is doing what in this task?. Due to this last question it is the place where negotiation is possible. The goal management must be aware of the general situation of the person and the environment. For instance, if a task is performed and someone enters in the room then this event might generate a switch to another task. Then a new task manager must be activated.

\section{Task management}

Here is the place where the plan proposed by the goal manager is executed. It looks to the progression of the plan and adapts the plan to local constraints. It verifies if all participants are working for the goal. It estimates the existence of potential dangerous situation. It verify the engagement of the human in the task. A set of task manager is present and one is active, the one running with the human, and the other one are suspended depending on event of the environment.

\section{Emotional state management}

The human model will take care of the comfort of the human. The stress reduction will be provided be predictability of the companion action. The tiredness of the human is measure and conflict avoidance taken into account. This emotional state computing is depending of the task running. For instance is the task is dangerous then the stress potentially increased. So the goal managers provides important informations on the property of the running task and the task manager gives informations on the actual situation of the task.

\section{Communication}

The specific vocabulary associated to the on-going task is used. This vocabulary can be verbal or non-verbal. The communication respects social norms. It is also the place where the authority is expressed based on the power repartition over the task.

\section{CONCLUSION}

In this paper we have presented a set of four necessary modules for software architecture to compute an artificial companion. This set is founded on an analysis of the criteria's used to analyse the interaction of human an digital devices and on dimensions of team coordination between man and robots.

\section{References}

[1] Davis, F.D., 1989. Perceived usefulness, perceived ease of use, and user acceptance of information technology. MIS Quarterly 13, 319-339

[2] Nielsen, J., 1993. Usability Engineering. Academic Press, New-York.

[3] Brad A. Myers, A Brief History of Human Computer Interaction Technology Carnegie Mellon University School of Computer Science Technical Report CMU-CS96-163, dec 1996

[4] Gary Klein \& all, Ten Challenges for Making Automation a "Team Player" in Joint Human-Agent Activity, IEEE Intelligent Systems 2004

[5] Ajzen, I., 1991. The theory of planned behavior. Organizational Behavior and Human Decision Processes 50, 179-211.

[6] S. Coradeschi, \& al (2006) Human-Inspired Robots. IEEE Intelligent Systems 21(4), 74-85

[7] Pesty, S and Duhaut, D (2011) Acceptability in interaction - From robots to Embodied Conversational Agent, Int conf on computer graphics theory and applications GRAPP 2011, 5-7 march Algarve Portugal.

[8] Ortony A (2003), On making believable emotionaml adents believable, In R. Trappl, P. Petta \& S.Payr (Eds), 
Emotions in humans and artefacts, Cambrodge, MA: MIT Press

[9] J.Bates (1994) The role of emotion in believable agents, Communications of the ACM 37, 122-125

[10] Berscheid, E and Reis, H (1998) Attraction and close relationships, The handbook od social psychology ISBN0-19-521376-9 193-281.

[11] Ewbank M.P, Barnard P.J \& all (2009) The amygdale response to images with impact, SCAN 4, 127133.

[12] Hind R. (1996) Describing relationships, The diversity of human relationships, Cambridge university press

[13] Poggi, I., al. (2005) Greta: A believable embodied conversational agent. Text, Speech and Language Technology, 2005, Volume 27

[14] Nemery, A., Brangier, E., \& Kopp, S. (2011). How the use of persuasive criteria can enhance the response rate of a business web survey: one empirical validation of the eight persuasive interaction criteria. Proceedings of Business and Information 2011, Bangkok, Volume 8, ISSN 1729-9322, 2011

[15] Kerstin Dautenhahn. Socially intelligent robots: dimensions of human robot interaction. Philosophical Transactions of the Royal Society of London- Series B: Biological Sciences, vol. 362, no. 1480, pages 679-704, 2007.

[16] S.Pesty, D.Duhaut Artificial Companion: building a impacting relation Robotics and Biomimetics IEEE-Robio 2011 December 7-11m 2011

[17] M. Grandgeorge, D. Duhaut Human-Robot : from Interaction to Relation Clawar 14th International Conference on Climbing and Walking Robots Paris september 6-8, 2011 